\title{
Cross-cultural impressions of leaders' faces: Consensus and predictive validity
}

\author{
Nicholas O. Rule ${ }^{\mathrm{a}, *}$, Keiko Ishii ${ }^{\mathrm{b}}$, Nalini Ambady ${ }^{\mathrm{c}}$ \\ a Psychology Department, University of Toronto, 100 St. George Street, Toronto, ON, Canada, M5S $3 G 3$ \\ b Psychology Department, Kobe University, Kobe, Japan \\ c Psychology Department, Tufts University, Boston, MA, United States
}

\section{A R T I C L E I N F O}

\section{Article history:}

Received 3 November 2010

Received in revised form 22 April 2011

Accepted 30 May 2011

\section{Keywords:}

Culture

Consensus

Accuracy

Face perception

Leadership

\begin{abstract}
A B S T R A C T
Across cultures, people tend to show high agreement in their impressions of others. But do these impressions predict external outcomes? Here we tested the predictive validity of trait judgments of the faces of Japanese and American targets, as rated by Japanese and American perceivers. Participants rated the faces of Japanese and American Chief Executive Officers of major companies. These judgments showed high agreement within and across cultures. In addition, judgments of power-related traits predicted the company profits of American CEOs, whereas judgments of warmth-related traits did not. However, neither power nor warmth predicted the company profits of Japanese CEOs, implicating longstanding cultural differences in company organization and business practices in the US versus Japan. Together, these data show both cross-cultural agreement between perceivers and targets but also cross-cultural differences in the relevance or application of particular trait information based on facial judgments.
\end{abstract}

(c) 2011 Elsevier Ltd. All rights reserved.

\section{Introduction}

Our impressions of people based just on their faces can substantially impact both our personal choices (e.g., whether to approach or avoid someone; Adams \& Kleck, 2003) as well as our group-level choices (e.g., whether to vote for someone in an election; Little, Burriss, Jones, \& Roberts, 2007). Although our automatic, snap judgments of others can be highly consequential (see Zebrowitz, 1997), most of what we know of these effects has been restricted to a single culture. The present work investigated the consequences of first impression judgments across cultures.

One related area of research that has been very well developed is the study of emotion recognition across cultures. Ekman, Sorensen, and Friesen (1969) showed that individuals from a diverse set of cultures (i.e., Borneo, Brazil, Japan, New Guinea, and the US) agreed in their assessments of emotions based on facial expressions. Although there is some variation within these effects (e.g. Russell, 1994), this body of literature has largely suggested that emotion recognition is universal across cultures for at least a basic set of core emotions (e.g., Ekman \& Friesen, 1971). Yet there is also evidence of significant variability within these effects. That is, although individuals may show above-chance accuracy in their judgments of some emotional expressions across cultures, they may be more accurate when judging the expressions of people from their own culture versus other cultures (Elfenbein \& Ambady, 2002).

Outside of the domain of emotion recognition, several traits related to personality and appearance seem to be reliably judged across perceiver and target cultures. McArthur and Berry (1987) found very high agreement between American and Korean individuals' perceptions of the facial maturity (babyfacedness) of Americans' faces. Moreover, Zebrowitz, Montepare,

\footnotetext{
* Corresponding author. Tel.: +1 416978 3948; fax: +1 4169784811

E-mail address: rule@psych.utoronto.ca (N.O.Rule).
} 
and Lee (1993) showed that Black American, White American, and Korean perceivers all agreed in their judgments of samerace and opposite-race faces for a host of traits (i.e., age, attractiveness, babyfaceness, honesty, naivete, submissiveness, and warmth). Similarly, Cunningham, Roberts, Barbee, Druen, and Wu (1995) found high same-culture and other-culture agreement for ratings of facial attractiveness among Black Americans, White Americans, Hispanic immigrants, and Taiwanese immigrants for targets from all of these groups. Finally, Albright et al. (1997) examined American and Chinese perceivers' judgments of multiple traits, which they clustered into the Big-5 personality traits (extraversion, agreeableness, conscientiousness, emotional stability/neuroticism, and culture/openness to experience). Although they found very high within-culture consensus on all of these traits when rating other-culture faces (with the exception of Chinese perceivers' judgments of Americans' conscientiousness), they found full cross-cultural agreement only for judgments of extraversion and agreeableness. In addition, Rule et al. (2010) found that Japanese and American perceivers' ratings of the faces of political candidates from both cultures were significantly correlated for a multitude of traits: competence, dominance, facial maturity, likeability, and trustworthiness.

One question that arises from such subjective impressions is whether they are valid. Interpersonal consensus is sometimes used as a means of validating judgments of others (Funder, 1987; Kruglanski, 1989) and may be particularly valid when the consensus extends across highly different cultures. Perhaps a better way of determining the validity of impressions is to compare them against an external criterion. In the emotion recognition literature, perceivers' judgments are compared against the emotion that the target was intending to express during stimulus creation. For personality traits, however, establishing a parallel criterion can be slightly more elusive, typically relying on individuals' own reports of their selfperceived traits. Another criterion to assess the degree to which a judgment of a trait is meaningful is to assess its predictive validity. For instance, Rule and Ambady (2008) reported that American participants showed high agreement in their ratings of traits from the faces of same-culture Chief Executive Officers (CEOs) of Fortune 1000 companies. They also found that these perceivers' judgments significantly corresponded to an external, objective measure of the CEOs' success-the amounts of profits that their companies made. Thus, not only were the perceivers' subjective assessments of the faces in accord with one another, these assessments could be validated by showing that they predicted an ecologically valid and consequential outcome measure.

The current investigation sought to combine the study of cross-cultural consensus in trait judgments with the study of the consequences of face-based first impression judgments. To do so, we examined American and Japanese perceivers' impressions of personality traits from the faces of American and Japanese CEOs and related these to an objective outcome criterion: the CEOs' companies' profits. Following the procedures of Rule and Ambady (2008), perceivers were asked to make judgments of five traits, representing two underlying composite variables: Power (a composite of competence, dominance, and facial maturity ratings) and Warmth (a composite of likeability and trustworthiness ratings). In Study 1 , American (Study 1A) and Japanese (Study 1B) perceivers judged the faces of American CEOs and in Study 2 both American (Study 2A) and Japanese (Study 2B) perceivers judged the faces of the CEOs from major Japanese companies on the same traits. We compared American and Japanese perceivers' judgments to measure cross-cultural agreement. In addition, we related these judgments to measures of the CEOs' companies' success.

Following the work on cross-cultural consensus (e.g., Zebrowitz et al., 1993), we expected to find high agreement between American and Japanese perceivers' judgments of at least some of the traits (Albright et al., 1997). Additionally, if American and Japanese perceivers agreed in their perceptions of the faces, we would expect that Japanese perceivers' judgments should predict CEOs' company profits, as did American perceivers' judgments in the previous work (Rule \& Ambady, 2008). However, given the differences between American and Japanese business models, we were uncertain whether these facebased impressions would significantly relate to Japanese CEOs' companies' success. For example, Rule et al. (2010) found that Japanese voters seemed to prefer candidates who were perceived to be high in warmth, whereas American voters preferred candidates perceived to be high in power. Given that American CEOs' success is also predicted by power, it is possible based on Rule et al.'s (2010) data that Japanese CEOs' success might be predicted by warmth. However, since the outcomes of elections are reflective of voters' values and the financial success of companies is not, it is possible that power might predict CEO success in both cultures, or that the relationship between facial appearance and success may only apply to American executives.

One reason to expect differences between the two cultures is that Japanese and American companies are distinct in their organizational structure. Wiersema and Bird (1993), for example, described how Japanese companies are typically led by cohesive and homogeneous cliques (habatsu). These cohorts of executives are characterized by much stronger bonds than the analogous relationships seen among American CEOs (the so-called "old boys network"). Intense socialization within these habatsu promotes strong intra-group loyalty, precludes outsiders from coming into the top management teams and boards of directors, and limits CEO candidates to within the group (Kim, 2004). One consequence of this is that Japanese business relations appear to favor long-term relationships, rather than those that may promote the best short-term opportunities, leading to inculcated leadership and a lifetime employment system (see Yamagishi, Cook, \& Watabe, 1998; Yoshikawa, Phan, \& David, 2005). This process is distinct from American companies who often rely on cross-organizational hiring to diversify their top management teams and boards of directors (e.g., Chan, 1996). Thus, it is possible that the perceived or actual traits of Japanese CEOs may be less important to their appointment than their connections and affiliations within the habatsu, potentially limiting the relationship between perceived CEO traits and company performance (Kim, 2004; Wiersema \& Bird, 1993). 
Such a strong intra-company focus is believed not only to affect CEO selection but to affect company dynamics, as well. Bhappu (2000), for instance, described Japanese companies as applying a family model to executive-worker relations. The relationship between executives and employees therefore tends to be fairly paternalistic (e.g., Ayman, 1993; Jung \& Avolio, 1998). Unlike American companies, CEOs and members of management in Japan are described as putting the interests of shareholders beneath the interests of the employees' welfare (David, O'Brien, Yoshikawa, \& Delios, 2010; Yoshimori, 1995). This not only affects the CEOs' behavior, it also affects business strategy by insulating companies from the pressures of shareholders. Japanese companies are usually more interested in long-term financial goals (such as gaining market share) than in short-term goals (such as increasing annual profits; David et al., 2010; Kaplan, 1994; Yamagishi et al., 1998). Thus, financial performance measures may not relate to perceptions of Japanese CEOs as they do for American CEOs because of cultural differences in business goals.

Altogether, these differences may result in distinct outcomes for the relationships between trait impressions and CEO profits in the two cultures. We therefore hypothesized that the present investigation may provide evidence of cross-cultural similarities in perception but cross-cultural differences in outcomes.

\section{Study 1: American CEOs}

Previous work has shown that judgments of traits from the faces of American CEOs corresponded to their companies' financial success. To test whether this information is culturally specific and retrievable only by same-culture perceivers, we sought to repeat this test with a sample of perceivers from a very different culture: Japan. Thus, in Study $1 \mathrm{~A}$ we repeated the study conducted by Rule and Ambady (2008) in which American participants rated the faces of American CEOs and in Study 1B we extended this investigation by asking Japanese participants to make the same judgments.

\subsection{Study 1A: American perceivers rating American CEOS}

Previous research reported the surprising finding that the success of CEOs' companies could be predicted based on judgments of the faces of their leaders (e.g., Rule \& Ambady, 2008). The present study aimed to validate those findings via replication with a new sample and to obtain the data necessary to conduct a cross-cultural comparison between American and Japanese perceivers' ratings of the faces of American CEOs.

\subsubsection{Method}

2.1.1.1. Participants. Twenty-eight undergraduates ( $n=19$ females) at an American university participated for partial credit in an introductory psychology course.

2.1.1.2. Stimuli. Stimuli consisted of those used by Rule and Ambady (2008). That is, photos of the top 25 and bottom 25 CEOs from the Fortune 1000: 2006 were downloaded from the CEOs' company websites and/or annual reports. Each photo was then cropped to show only the CEO's face, limited to the bottom of the chin, top of the hair, and the more extreme of either the hair or ears. Cropped photos were then converted to grayscale and standardized to a common height, allowing for proportion-based variation in width. One CEO was excluded from testing because she was the only female CEO within these ranks and a second CEO was excluded from testing because previous testing had shown him to be a statistical outlier (see Rule \& Ambady, 2008). The final stimulus set therefore consisted of 48 male CEOs' faces, all of whom were Caucasian.

Information about company performance (gross profits or "revenues", and net profits or "profits") were obtained from the Fortune 1000 listing for 2006 (fiscal year 2005; Fortune Magazine, 2006a). In cases where information about gross profits and net profits were not available, this information was obtained from the companies' annual reports or from Google Finance. These values served as the dependent measures in the analyses.

2.1.1.3. Procedure. Procedures were identical to those used in the trait-rating condition of Rule and Ambady (2008). Specifically, participants were instructed that they would be seeing a series of faces on a computer screen and that they would be rating these faces on various traits along 7-point scales, ranging from 1 (Not at all $\mathrm{X}$ ) to 7 (Very $\mathrm{X}$ ). Participants rated five traits: competence (Cronbach's $\alpha=.74$; ICC $=.15,95 \% \mathrm{CI}=.09-.26$ ), dominance (Cronbach's $\alpha=.75$; ICC $=.08,95 \% \mathrm{CI}=.04-.15$ ), facial maturity (Cronbach's $\alpha=.74$; ICC $=.22,95 \% \mathrm{CI}=.14-.35$ ), likeability (Cronbach's $\alpha=.77$; ICC $=.17,95 \% \mathrm{CI}=.11-.28$ ), and trustworthiness (Cronbach's $\alpha=.71$; ICC $=.16,95 \% \mathrm{CI}=.10-.27$ ). Traits were evaluated in randomly ordered blocks within which all 48 faces were presented in a random order. Before each block, participants were given new instructions that informed them of the next trait and scale that they would be using to rate the faces. During the ratings, the scale and anchors were presented at the bottom of the screen. All stimuli were presented and responses recorded using DirectRT software. After the participants rated all of the faces, they were asked to indicate whether they recognized any of the faces that they saw during the experiment; none did.

\subsubsection{Results and discussion}

Ratings of the faces were averaged across participants, yielding a mean score for each target on each trait. Two CEOs were excluded from analysis because their companies had been acquired (merged with another company) during fiscal year 2005. Following Rule and Ambady (2008), scores for competence, dominance, and facial maturity were averaged into a single 
Table 1

Trait correlations between Japanese and American perceivers' judgments of the faces of American CEOs.

\begin{tabular}{|c|c|c|c|c|c|c|}
\hline & \multicolumn{2}{|c|}{ American perceivers } & \multicolumn{2}{|c|}{ Japanese perceivers } & \multirow[t]{2}{*}{$r$} & \multirow[t]{2}{*}{$r^{\prime}$} \\
\hline & $M$ & $S D$ & $M$ & $S D$ & & \\
\hline Power & 4.35 & .43 & 4.56 & .43 & $.70^{* * *}$ & .80 \\
\hline Competence & 4.28 & .45 & 4.59 & .50 & $.65^{* * *}$ & .84 \\
\hline Dominance & 4.23 & .61 & 4.37 & .53 & $.58^{* * *}$ & .71 \\
\hline Facial maturity & 4.55 & .62 & 4.71 & .50 & $.70^{* * *}$ & .85 \\
\hline Warmth & 3.92 & .47 & 4.22 & .48 & $.64^{* * *}$ & .75 \\
\hline Likeability & 3.85 & .46 & 4.31 & .51 & $.59^{* * *}$ & .73 \\
\hline Trustworthiness & 3.99 & .52 & 4.12 & .51 & $.64^{* * *}$ & .81 \\
\hline
\end{tabular}

Note: $r^{\prime}$ values not subject to significance testing.

*** $p<.001$.

composite score called Power and scores for likeability and trustworthiness were averaged into a single composite score called Warmth. ${ }^{1}$

As found in earlier work (Rule \& Ambady, 2008), Power was significantly correlated with net profits $[r(46)=.31, p=.03]$ but not gross profits $\left[r(46)=.14, p=.33\right.$ ], and Warmth was related to neither measure $(r$ 's $<|.09|$, $p$ 's $>.54){ }^{2}$ Null effects for gross profits are not surprising, given that gross profits are highly influenced by company size (e.g., Rule \& Ambady, in press). Indeed, although Fortune bases its rankings on gross profits, they are typically a poor indicator of the success of a company. For example, automobile manufacturers in the US yield some of the highest gross profits. However, because their operating costs are so high, their net profits are quite low and, in fiscal year 2005, most American automobile manufacturers reported stunning losses.

\subsection{Study 1B: Japanese perceivers rating American CEOs}

Although Americans' judgments of the faces of CEOs can be predictive of their success, it is unknown whether the ability to extract this information from targets' faces is culturally dependent. Study $1 \mathrm{~B}$ therefore examined whether judgments of the same traits by Japanese participants would also predict the success of American CEOs and these ratings were compared with those made by the American participants in Study $1 \mathrm{~A}$.

\subsubsection{Method}

Thirty-eight undergraduates ( $n=15$ females) at a Japanese university rated the same faces from Study $1 \mathrm{~A}$ following identical procedures (one female participant's data were incomplete due to a computer error and were therefore excluded from analysis). The only difference between Studies $1 \mathrm{~A}$ and $1 \mathrm{~B}$ was that all materials were translated into Japanese and back-translated to English to assure consistency in meaning; as these same measures had been vetted in previous research (Rule et al., 2010), no adjustments were needed following translation. Inter-rater reliability among the participants was similar in magnitude as it was for the American participants in Study 1A: competence (yuno; Cronbach's $\alpha=.80$; ICC =.16, 95\% CI=.11-.26), dominance (shihaiteki; Cronbach's $\alpha=.90$; ICC =.15, 95\% CI=.10-.24), facial maturity (seijukushita kao; Cronbach's $\alpha=.90$; ICC =.16, 95\% CI =.10-.25), likeability (konomashisa; Cronbach's $\alpha=.84 ; \mathrm{ICC}=.22,95 \% \mathrm{CI}=.15-.34$ ), and trustworthiness (sinraidekiru; Cronbach's $\alpha=.87$; ICC $=.28,95 \% \mathrm{CI}=.20-.40$ ). No participants recognized any of the targets.

\subsubsection{Results and discussion}

As above, ratings of the faces were averaged across participants, yielding a mean score for each target on each trait and two CEOs were excluded from analysis because their companies had been acquired (merged with another company) during fiscal year 2005. Scores for competence, dominance, and facial maturity were averaged into a single composite score called Power and scores for likeability and trustworthiness were averaged into a single composite score called Warmth. Both these composites and the individual traits showed high cross-cultural agreement: all $r$ 's $\geq .58$, all $p$ 's $<.001$ (see Table 1 ). Additionally, correction for attenuation (e.g., Kenny, Albright, Malloy, \& Kashy, 1994; Kenny \& West, 2008) of these crosscultural correlations resulted in even greater cross-cultural consistency: all $r^{\prime \prime} \mathrm{s} \geq .71$ (see Table 1). Thus, American and Japanese raters showed high cross-cultural consistency and agreement in their ratings of the American CEOs; adding to our knowledge of the traits that can be judged with cross-cultural consistency across various domains (cf. Albright et al., 1997; Rule et al., 2010; Zebrowitz et al., 1993).

\footnotetext{
1 Notably, Rule et al. (2010) measured judgments of the same traits cross-culturally and found that competence loaded differently onto Power and Warmth for Japanese versus American perceivers' judgments. If we remove competence from the analyses here, as was done there, the results reported throughout the present studies are no different.

2 Two companies reported gross profits more than three standard deviations greater than the mean for the set and one of these companies reported net profits more than three standard deviations from the mean. We therefore repeated these analyses replacing these values with the values marking the upper bound. After rounding to the nearest hundredth, this analysis yielded exactly the same correlation coefficients as when the raw values were used. Thus, these values do not appear to have had great influence on the present results.
} 
The Japanese participants' ratings also predicted the US CEOs' success. Scores for Power significantly correlated with CEOs' net company profits $[r(44)=.37, p=.01]$ but not with CEOs' gross company profits $[r(44)=.20, p=.18]$. Moreover, scores for Warmth predicted neither net profits $[r(44)=.01, p=.94]$ nor gross profits $[r(44)=.02, p=.89]$, as above. American and Japanese perceivers therefore exhibited strong agreement in the way that they perceived the faces of American CEOs and these judgments predicted the CEOs' outcomes. These data therefore provide evidence of both convergent validity across rater culture, as well as predictive validity in terms of the efficacy of the judgments to predict a real-world outcome.

\section{Study 2: Japanese CEOs}

Study 1 showed that Japanese perceivers' judgments of the faces of American CEOs strongly agreed with same-culture Americans' judgments of the faces and, thus, were predictive of the CEOs' companies' success. That is, judgments of perceivers in one culture were related to an objective indicator of performance in a second, very different culture. As Study 1 employed only American targets, however, Study 2 sought to extend these effects across cultures by asking American (Study 2A) and Japanese (Study 2B) participants to perform the same judgments of the faces of Japanese CEOs.

\subsection{Study 2A: American perceivers rating Japanese CEOs}

Americans' judgments of traits from the faces of American CEOs predicted their companies' success. Study 2A tested whether Americans' judgments might also predict the success of a group of targets from a different culture: Japan. Thus, we sought to examine whether the relationship between judgments of individuals' faces and those individuals' success as leaders might vary depending on the targets' culture.

\subsubsection{Method}

3.1.1.1. Participants. Thirty-two undergraduates ( $n=21$ females) at an American university participated for partial credit in an introductory psychology course. One participant's data were lost due to a computer error.

3.1.1.2. Stimuli. Photos of 43 CEOs from the Japanese subset of Fortune's Global 500: 2006 (Fortune Magazine, 2006b) were downloaded from their companies' websites or annual reports. Fortune's Global 500 ranks the top companies internationally and provides sub-listings for individual countries. In the case of Japan, 70 companies were ranked in the 2006 listing, which is based on the 2005 fiscal year. Of these 70 companies, we were able to obtain photos and financial information for the CEOs of 41 companies; two CEOs were excluded from data collection because they were not Japanese. We then standardized these photos using the same procedures as in Study 1. Of relevance, judgments of affective expression (from 1 Neutral to 4 Happy to 7 Very happy) from the faces of the American $(M=3.41, S D=1.35)$ and Japanese $(M=3.24, S D=1.21)$ CEOs showed no significant differences in pre-testing: $t(83)=.60, p=.55$.

3.1.1.3. Procedure. The experimental procedures were identical to that of Study 1a except that the photos of the Japanese targets were used. No participants reported any recognition of any of the targets, and participants showed sufficient interrater reliabilities in their judgments: competence (Cronbach's $\alpha=.73$; ICC $=.29,95 \% \mathrm{CI}=.20-.43$ ), dominance (Cronbach's $\alpha=.88$; ICC $=.21,95 \% \mathrm{CI}=.14-.34$ ), facial maturity (Cronbach's $\alpha=.88 ; \mathrm{ICC}=.29,95 \% \mathrm{CI}=.20-.43$ ), likeability (Cronbach's $\alpha=.92 ; \mathrm{ICC}=.23,95 \% \mathrm{CI}=.16-.36$ ), and trustworthiness (Cronbach's $\alpha=.88 ; \mathrm{ICC}=.20,95 \% \mathrm{CI}=.13-.32$ ).

\subsubsection{Results and discussion}

Participants' scores were averaged together for each target separately for each trait. The mean scores for competence, dominance, and facial maturity were then averaged together to form a composite score called Power and the mean scores for likeability and trustworthiness were averaged together to form a composite score called Warmth, as in Study 1.

To test whether perceptions of personality traits would predict the success of Japanese CEOs, as they do for American CEOs, we then correlated the Power and Warmth scores for each target with his company's gross profits and net profits. Neither Power $[r(37)=-.29, p=.08]$ nor Warmth $[r(37)=.01, p=.93]$ showed a significant relationship with gross profits. Similarly, neither Power $[r(37)=-.04, p=.80]$ nor Warmth $[r(37)=.06, p=.71]$ showed a significant relationship with net profits.

Unlike perceptions of American CEOs' faces, American participants' ratings of personality traits from the faces of Japanese CEOs showed no relationship to the actual success of their company. This finding was not unexpected, given the differences in the organizational structure of companies in the US and Japan (see Bhappu, 2000). Given that Japanese companies are often characterized by cohesive cliques and that CEOs are often selected from within a group of insiders (Wiersema \& Bird, 1993), it is possible that perceptions of American CEOs may correspond to their companies' success because the CEOs' actual traits may be more likely to play a role in their acquisition of the CEO position. This proposition is only speculative, however.

Indeed, there are many alternative explanations for the presence of these null effects. For instance, perceiver culture may affect judgments of Japanese CEOs differently than it does judgments of American CEOs-perhaps because Japanese are exposed to American media and culture more than Americans are exposed to Japanese media and culture. Study 2B 
Table 2

Trait correlations and descriptive statistics for American and Japanese perceivers' judgments of the faces of Japanese CEOs.

\begin{tabular}{|c|c|c|c|c|c|c|}
\hline & \multicolumn{2}{|c|}{ American perceivers } & \multicolumn{2}{|c|}{ Japanese perceivers } & \multirow[t]{2}{*}{$r$} & \multirow[t]{2}{*}{$r^{\prime}$} \\
\hline & $M$ & $S D$ & $M$ & $S D$ & & \\
\hline Power & 4.68 & .48 & 4.60 & .38 & $.66^{* * *}$ & .72 \\
\hline Competence & 4.72 & .46 & 4.69 & .50 & $.56^{* * *}$ & .71 \\
\hline Dominance & 4.62 & .61 & 4.40 & .48 & $.42^{* *}$ & .49 \\
\hline Facial maturity & 4.71 & .66 & 4.92 & .61 & $.63^{* * *}$ & .70 \\
\hline Warmth & 4.35 & .71 & 3.91 & .51 & $.34^{*}$ & .37 \\
\hline Likeability & 4.34 & .78 & 3.96 & .52 & $.40^{* *}$ & .44 \\
\hline Trustworthiness & 4.35 & .69 & 3.86 & .56 & $.31^{*}$ & .35 \\
\hline
\end{tabular}

therefore sought to investigate the role of perceiver culture further by asking Japanese perceivers to provide judgments of the Japanese CEOs.

\subsection{Study 2B: Japanese perceivers rating Japanese CEOs}

Study 1 showed that judgments of American CEOs by American perceivers were significantly correlated with judgments made by Japanese perceivers. Given the correlations between these perceptions, Japanese participants' judgments were also significantly correlated with American CEOs' companies' profits; as were American perceivers' judgments in Study 1A and in past work (Rule \& Ambady, 2008). Study 2A then tested American perceivers' judgments of Japanese CEOs but found no relationship between their perceptions and the CEOs' companies' financial performance. One reason for the absence of this effect might be because American perceivers are not attuned in their judgments of Japanese faces. Study $2 \mathrm{~B}$ therefore explored whether same-culture expertise in perceiving the faces of Japanese CEOs might dissociate these asymmetrical effects. Thus, Japanese participants provided trait ratings of the Japanese CEOs' faces and these judgments were assessed against both (a) company profits, and (b) American participants' judgments in Study 2A.

\subsubsection{Method}

Thirty-seven undergraduates ( $n=18$ females) at a Japanese university rated the competence (Cronbach's $\alpha=.87$; ICC $=.11$, $95 \% \mathrm{CI}=.06-.21$ ), dominance (Cronbach's $\alpha=.80$; ICC $=.16,95 \% \mathrm{CI}=.09-.30$ ), facial maturity (Cronbach's $\alpha=.87 ; \mathrm{ICC}=.22,95 \%$ $\mathrm{CI}=.13-.38$ ), likeability (Cronbach's $\alpha=.88 ; \mathrm{ICC}=.15,95 \% \mathrm{CI}=.08-.28$ ), and trustworthiness (Cronbach's $\alpha=.88 ; \mathrm{ICC}=.08,95 \%$ $\mathrm{CI}=.04-.18$ ) of all 39 of the faces of Japanese CEOs from Study 2A following the procedures used in Study 1B. One participant recognized a CEO and was therefore excluded from analysis.

\subsubsection{Results and discussion}

Ratings for each CEO were averaged across participants for each trait. Means for competence, dominance, and facial maturity were again averaged together into a Power composite and means for likeability and trustworthiness were averaged into a Warmth composite. The individual and composite trait ratings of the Japanese participants in this study and the American participants in Study 2A showed significant cross-cultural agreement (see Table 2). However, similar to the results of Study 2A, Japanese participants' judgments of the CEOs were not correlated with the financial performance measures. Neither Power nor Warmth was significantly correlated with gross profits [Power: $r(37)=-.07, p=.65$; Warmth: $r(37)=-.26$, $p=.11$ ] or net profits [Power: $r(37)=.02, p=.89$; Warmth: $r(37)=-.18, p=.28$ ]. Unlike American CEOs, then, perceptions of Japanese CEOs' faces do not predict the CEOs' companies' success.

The absence of a relationship between perceptions of Japanese CEOs' faces and the financial performance of their companies therefore generalizes to both same-culture and other-culture perceivers. Thus, there appears not to be a relationship between perceptions of Japanese CEOs' and their companies' profits. As discussed in Study 2A, this null effect may exist for a multitude of reasons. One difference between CEOs in the US versus CEOs in Japan may be the means by which they acquire their positions (selection from an open pool versus selection from a small and cohesive internal group). Thus, the difference here may be that American CEOs' well-vetted selection leads to more powerful-looking CEOs managing more successful companies in the US. However, this conclusion is tenuous as it rests on the observation of a null effect and as other possibilities (such as differences in company goals) might also contribute to the absence of an effect. That notwithstanding, these data do show that American and Japanese perceivers exhibit significant cross-cultural agreement for judgments of faces, thereby extending and reinforcing our knowledge of the cross-cultural perception of traits from facial cues (Albright et al., 1997; Rule et al., 2010; Zebrowitz et al., 1993). 


\section{General discussion}

American and Japanese perceivers showed high cross-cultural agreement in their perceptions of same-culture and otherculture CEOs' faces. In addition, participants' judgments significantly related to the financial performance of American CEOs' companies but did not significantly relate to the financial performance of Japanese CEOs' companies.

Although a great deal of research has documented the accuracy of recognizing emotional expressions across cultures (e.g., Ekman et al., 1969), the current data extend our knowledge of cross-cultural consistency in judgments of individuals' traits from their faces. Previous studies have shown cross-cultural agreement for judgments of faces along several physiognomic (Cunningham et al., 1995; Zebrowitz et al., 1993) and personality (Albright et al., 1997; Rule et al., 2010; Zebrowitz et al., 1993) traits. The present findings demonstrate that the consistency of judgments for competence, dominance, facial maturity, likeability, and trustworthiness is not restricted to perceptions of only political leaders. As the present work did examine leaders in a different domain, however, it may still be of relevance for future research to examine whether these are traits that are consistent for leaders, in particular, or if they might apply to ordinary citizens and lower-ranking executives, as well.

Moreover, corroborating previous work with American perceivers, Japanese perceivers' judgments of American CEOs' faces also predicted the American companies' profits; and Japanese perceivers' judgments were significantly correlated with those of American perceivers. These findings therefore suggest that the relationship between perceptions of American CEOs' faces and their professional success (as measured by the profits earned by the companies they lead) occurs independently of the perceivers' culture. In essence, Japanese and American perceivers were equivalent as judges in attaining these effects.

American and Japanese perceivers agreed in their trait judgments of the Japanese CEOs' faces but their ratings did not predict Japanese companies' performance. Given that the current perceiver-effects are cross-culturally consistent but the current target-effects vary by culture, a cultural difference between American and Japanese CEOs may account for differences in target effects. Although firm conclusions cannot be drawn from null findings, the comparison between the cultures indeed suggests that there is some difference. Two possibilities may be cultural differences between the (1) goals and (2) organization of Japanese and American companies.

First, Japanese companies are often characterized by different business goals than those that are emphasized within American companies (e.g., Bhappu, 2000; David et al., 2010; Yamagishi et al., 1998). In particular, previous work has suggested that Japanese companies may favor growth and market-share over profits, and long-term business security over short-term business opportunity (David et al., 2010; Kaplan, 1994). Long-term financial goals may supersede short-term financial goals in Japan partly because employees' job security is seen as a premiere priority and because Japanese companies are relatively isolated from shareholder pressures (e.g., Yoshikawa et al., 2005). In contrast, American companies are typically driven by stock fluctuations and are often oriented towards the shareholders' interests over that of the employees (Yoshimori, 1995). These differences in focus may be responsible for the absence of an effect for Japanese CEOs because of cultural differences in the relevance of the criterion variable. In addition, it is noteworthy to consider the role that cultural differences in individual goals may also play in these effects. For instance, work on achievement motivation (e.g., McClelland, 1961) across cultures might suggest that individuals in Japan could be motivated towards goals related to securing harmony and interpersonal relationships, whereas those in the US could be motivated towards individual achievement (Maehr, 1974; see also Markus \& Kitayama, 1991; McClelland, 1985). These differences could contribute to the different attitudes about business practices when aggregated at the cultural level; however, further work will be needed to test this possibility directly.

Related to differences in goals are the overall differences in organization. The potentially paternalistic nature of management in Japanese companies not only serves to protect lower-ranking employees, it might also serve to restrict the selection of CEOs to a smaller, internal pool of candidates that is often characterized by entrenchment within the organization (Bhappu, 2000; Kim, 2004; Wiersema \& Bird, 1993; Yoshimori, 1995). Japanese companies are often characterized by the consistency of their leadership and very few career changes among executives. Indeed, investigation into the career histories of the Japanese CEOs in the current sample revealed that only two had ever changed their place of work. A particular individual's personality traits may be less of a determinant of his position or success in Japan than are his connections, relationships with others, or tenure within an organization. Thus, whereas earlier work (Rule et al., 2010) found that warmth predicted the electoral success for Japanese political candidates because warmth is highly valued in leaders in Japan, it may not have been predictive of company success in the current domain-despite the fact that it is valued among business leaders-because the means of acquiring leadership positions in business is determined by different factors that, in addition, are not as closely tied to company performance.

This is not to say that the traits perceived from faces actually correspond to the actual possession of these traits. Rather, it simply means that the CEOs are perceived to hold these traits. One possible mechanism by which the American CEOs who are perceived to be more powerful acquire positions as CEOs of more profitable companies could be that individuals who express a more powerful appearance are more likely to be selected by more profitable companies. The absence of an effect for Japanese CEOs' perceived traits and their success may provide support for this hypothesis. Recall that the relative differences in perceived power and warmth among Japanese CEOs were not related to their companies' actual success, indicating that the perceived traits of Japanese CEOs may be unrelated to their companies' performance. Thus, it may be that American CEOs who look powerful acquire more successful positions, thereby exhibiting a relationship between their perceived traits and their companies' financial performance. If Japanese CEOs typically acquire CEO positions through connections, rather than through competitive selection, it would be reasonable that such a relationship would be absent. Yet, as there may be many 
reasons for why a significant relationship between Japanese CEOs and personality was not found in the current work, these conclusions are merely speculative.

Indeed, further work may be useful in deconstructing these effects. Additional cross-cultural work on the prediction of objective outcomes related to leadership could help to clarify some of the speculations related to the present conclusions. The work could also be improved with larger sample sizes, even though the level of inter-rater agreement for all traits was above threshold (e.g., Meyers, Gamst, \& Guarino, 2006), and perhaps with a different cohort of CEO faces, as compared to those used in Rule and Ambady (2008). Moreover, increased information about the traits that perceivers use in making these judgments would also be helpful. Although traits such as dominance and facial maturity are characterized by very well-defined features (e.g., heavy jaw and brow ridge, prominent cheekbones, angular bone structure; Zebrowitz, 1997; see also Kappas, Hess, Barr, \& Kleck, 1994), the presence of such features is not clearly apparent in the current faces. Much less is known about precisely what features make a face appear warm, though related work might suggest that features evincing babyfacedness (e.g., large forehead and eyes, flat cheekbones and brow ridge, rounded features and bone structure) might be responsible for perceptions of warmth or approachability among the faces (Berry \& Landry, 1997; Berry \& McArthur, 1985).

In conclusion, the current findings demonstrate that American and Japanese perceivers agreed in their judgments of traits from faces of their own and the other's culture. These data extend previous accounts of cross-cultural consensus for judgments from faces. In addition, these judgments were predictive of the company profits of American CEOs but showed no relationship with the company profits of Japanese CEOs, illuminating the potential effects of cultural differences at the level of how face-based information is applied within the targets' respective cultures.

\section{References}

Adams, R. B., Jr., \& Kleck, R. E. (2003). Perceived gaze direction and the processing of facial displays of emotion. Psychological Science, $14,644-647$.

Albright, L., Malloy, T. E., Dong, Q., Kenny, D. A., Fang, X., Winquist, L., et al. (1997). Cross-cultural consensus in personality judgments. Journal of Personality and Social Psychology, 72, 558-569.

Ayman, R. (1993). Leadership perception: The role of gender and culture. In R. M. Chemers, \& R. Ayman (Eds.), Leadership theory and research (pp. 137-165). San Diego, CA: Academic Press.

Berry, D. S., \& Landry, J. C. (1997). Facial maturity and daily social interaction. Journal of Personality and Social Psychology, 72, 570-580.

Berry, D. S., \& McArthur, L. Z. (1985). Some components and consequences of a babyface. Journal of Personality and Social Psychology, $48,312-323$.

Bhappu, A. D. (2000). The Japanese family: An institutional logic for Japanese corporate networks and Japanese management. Academy of Management Review, 25, 409-415.

Chan, W. (1996). External recruitment versus internal promotion. Journal of Labor Economics, 14, 555-570.

Cunningham, M. R., Roberts, A. R., Barbee, A. P., Druen, P. B., \& Wu, C. (1995). "Their ideas of beauty are, on the whole, the same as ours": Consistency and variability in the cross-cultural perception of female physical attractiveness. Journal of Personality and Social Psychology, 68, $261-279$.

David, P., O'Brien, J. P., Yoshikawa, T., \& Delios, A. (2010). Do shareholders or stakeholders appropriate the rents from corporate diversification? The influence of ownership structure. Academy of Management Journal, 53, 636-654.

Ekman, P., \& Friesen, W. V. (1971). Constants across cultures in the face and emotion. Journal of Personality and Social Psychology, 17, $124-129$.

Ekman, P., Sorensen, E. R., \& Friesen, W. V. (1969). Pan-cultural elements in facial displays of emotion. Science, 164, 86-88.

Elfenbein, H. A., \& Ambady, N. (2002). On the universality and cultural specificity of emotion recognition: A meta-analysis. Psychological Bulletin, 128, 203-235.

Fortune Magazine. (2006a, April 17). Fortune 1,000 annual rankings. Retrieved from http://money.cnn.com/magazines/fortune/fortune500/full_list/ index.html on 12 March 2011.

Fortune Magazine. (2006b, July 24). Fortune global 500 annual rankings. Retrieved from http://money.cnn.com/magazines/fortune/global500/2006/ countries/J.html on 12 March 2011.

Funder, D. C. (1987). Errors and mistakes: Evaluating the accuracy of social judgment. Psychological Bulletin, 101, 75-90.

Jung, D. I., \& Avolio, B. J. (1998). Examination of transformational leadership and group process among Caucasian- and Asian-Americans. Research in International Business and International relations, 7, 29-66.

Kaplan, S. N. (1994). Top executive rewards and firm performance: A comparison of Japan and the United States. Journal of Political Economy, $102,510-546$.

Kappas, A., Hess, U., Barr, C. L., \& Kleck, R. E. (1994). Angle of regard: The effect of vertical viewing angle on the perception of facial expressions. Journal of Nonverbal Behavior, 18, 263-280.

Kenny, D. A., Albright, L., Malloy, T. E., \& Kashy, D. A. (1994). Consensus in interpersonal perception: Acquaintance and the big five. Psychological Bulletin, $116,245-258$.

Kenny, D. A., \& West, T. V. (2008). Zero acquaintance: Definitions, statistical model, findings, and process. In N. Ambady, \& J. J. Skowrosnki (Eds.), First impressions (pp. 129-146). New York: Guilford.

Kim, H. (2004). When will my boss step down: Tenure rules in top executive changes in Japanese firms. Journal of Strategic Management, 17, 131-151.

Kruglanski, A. W. (1989). The psychology of being right: The problem of accuracy in social perception and cognition. Psychological Bulletin, 106, 395-409.

Little, A. C., Burriss, R. P., Jones, B. C., \& Roberts, S. C. (2007). Facial appearance affects voting decisions. Evolution and Human Behavior, $28,18-27$.

Maehr, M. L. (1974). Culture and achievement motivation. American Psychologist, 29, 887-896.

Markus, H. R., \& Kitayama, S. (1991). Culture and the self: Implications for cognition, emotion, and motivation. Psychological Review, 98, 224-253.

McArthur, L. Z., \& Berry, D. S. (1987). Cross-cultural agreement in perceptions of babyfaced adults. Journal of Cross-Cultural Psychology, 18, 165-192.

McClelland, D. C. (1961). The achieving society. New York: Free Press.

McClelland, D. C. (1985). How motives, skills, and values determine what people do. American Psychologist, 40, 812-825.

Meyers, L. S., Gamst, G., \& Guarino, A. J. (2006). Applied multivariate research: Design and interpretation. Thousand Oaks, CA: Sage.

Rule, N. O., \& Ambady, N. (2008). The face of success: Inferences of personality from Chief Executive Officers' appearance predict company profits. Psychological Science, 19, 109-111.

Rule, N. O., \& Ambady, N. (in press). Face and fortune: Inferences of personality from Managing Partners' faces predict their firms' financial success. The Leadership Quarterly, doi:10.1016/j.leaqua.2011.05.009.

Rule, N. O., Ambady, N., Adams, R. B., Jr., Ozono, H., Nakashima, S., Yoshikawa, S., et al. (2010). Polling the face: Prediction and consensus across cultures. Journal of Personality and Social Psychology, 98, 1-15.

Russell, J. A. (1994). Is there universal recognition of emotion from facial expression? A review of the cross-cultural studies. Psychological Bulletin, 115, $102-141$. 
Wiersema, M. F., \& Bird, A. (1993). Organizational demography in Japanese firms: Group heterogeneity, individual dissimilarity, and top management team turnover. Academy of Management Journal, 36, 996-1025.

Yamagishi, T., Cook, K. S., \& Watabe, M. (1998). Uncertainty, trust, and commitment formation in the United States and Japan. American Journal of Sociology, 104, 165-194.

Yoshikawa, T., Phan, P. H., \& David, P. (2005). The impact of ownership structure on wage intensity in Japanese corporations. Journal of Management, 31 , 278-300.

Yoshimori, M. (1995). Whose company is it? The concept of the corporation in Japan and the West. Long Range Planning, $28,33-44$.

Zebrowitz, L. A. (1997). Reading faces: Window to the soul? Boulder, CO: Westview Press.

Zebrowitz, L. A., Montepare, J. M., \& Lee, H. K. (1993). They don't all look alike: Individuated impressions of other racial groups. Journal of Personality and Social Psychology, 65, 85-101. 